\title{
Neuroendoscopy for Intracranial Arachnoid Cysts in Infants: Therapeutic Considerations
}

\author{
Subodh Raju ${ }^{1}$ Renuka Satyanarayana Sharma ${ }^{1} \quad$ Srilata Moningi ${ }^{2} \quad$ Jaleel Momin ${ }^{1}$ \\ ${ }^{1}$ Department of Neurosurgery, Kamineni Hospitals, Hyderabad, \\ Andhra Pradesh, India \\ 2 Department of Anesthesiology and Critical Care, Nizam's Institute of \\ Address for correspondence Subodh Raju, MS, MCh, Department of \\ Neurosurgery, Kamineni Hospitals, L.B. Nagar Hyderabad, Andhra \\ Pradesh, 500068, India (e-mail: subodh61raju@yahoo.co.in).
} Medical Sciences, Hyderabad, Andhra Pradesh, India

J Neurol Surg A 2016;77:333-343.

\begin{abstract}
Keywords

- neuroendoscopy

- arachnoid cyst

- hydrocephalus

- infants

Background The use of the endoscope for various cranial procedures is gradually expanding. Intracranial cystic lesions in the brain are one of the most attractive targets for this minimally invasive procedure, thus avoiding conventional craniotomy. These cystic lesions in the brain, namely arachnoid cysts, are congenital. Surgical treatment depends on clinical presentation, location, and age.

Patients A total of 13 patients $<1$ year of age with intracranial cysts were operated on between 2005 and 2013. Six presented with hydrocephalus, four presented with seizure, one with abnormal head movement, and two had large asymptomatic cysts. Four children had infratentorial arachnoid cysts; of these, three required a transaqueductal procedure. All the patients underwent endoscopic cystoventriculostomy and/or cystocisternostomy and third ventriculostomy in selected cases with a biopsy from the cyst wall.

Results Clinically and radiologically all children showed significant improvement with an average follow-up ranging from 8 months to 6 years. There were no intraoperative complications. Three children developed subdural hygroma that subsided with conservative treatment, and one child with pseudomeningocele required a cystoperitoneal shunt at a later date.

Conclusion A symptomatic intracranial arachnoid cyst or a large asymptomatic cyst are indications for neurosurgical intervention, and endoscopy is a good treatment option with the advantage of minimal invasiveness and fewer complications. Endoscopic surgery has to be tailored according to the location and presentation.
\end{abstract}

\section{Introduction}

Intracranial cysts are one of the most common conditions that come to a neurosurgeon's attention. They can be congenital or acquired. ${ }^{1,2}$ The most common intracranial cyst encountered is an arachnoid cyst.

Most arachnoid cysts remain asymptomatic throughout the life and are incidental findings on computed tomography (CT)/magnetic resonance imaging (MRI) performed for other

received

July 15, 2013

accepted after revision

September 15, 2014

published online

August 4, 2015

situations such as trauma. ${ }^{3}$ Only symptomatic and large intracranial cysts require treatment. In the present era of minimally invasive neurosurgery, an endoscopic procedure for an intracranial arachnoid cyst has made the treatment easier and safer.

Surgery for these cysts has to be tailored according their location. Data about the outcome of intracranial cysts in adults have been well reported, but the comparable data in children $<1$ year of age are still sparse. ${ }^{4}$ In the present study,

(c) 2016 Georg Thieme Verlag KG Stuttgart - New York
DOI http://dx.doi.org/ 10.1055/s-0034-1396434. ISSN 2193-6315. 
we evaluated the surgical approaches, indications, and outcome of endoscopic procedures performed at our institution for arachnoid cysts in different locations in infants and analyzed similar data reported in the literature.

\section{Methods and Materials}

A prospective study was performed in all pediatric patients admitted with arachnoid cysts in our institution from 2005 to 2013. Malignant iatrogenic postoperative cystic lesions and other cysts such as a Rathke cyst were excluded from the study. Detailed history and a thorough physical examination were performed in all cases. Data included age, sex, clinical symptoms, site, and location of cysts based on CT/MRI findings, surgical approach, and postoperative status. All patients had both preoperative and postoperative ophthalmologic checkups and psychomotor developmental assessments. Postoperative CT/MRI brain scans were performed in all patients after 3 to 6 months or as and when required. All patients had a minimum of a 6-month follow-up.

\section{Study Population}

The demographic data included 13 patients ( $M: F$ ratio $5: 8)<1$ year of age operated on during this period. Details of each case are described in - Table 1. The mean age was 5 months (range: 1-12 months). Three cases diagnosed antenatally were asymptomatic. Hydrocephalus was present in seven cases; four patients presented with seizures. Other symptomatology included infantile spasms (in one patient) and macrocephaly with involuntary head movements (in one patient). The follow-up period ranged from 8 months to 6 years.

\section{Location of Cysts}

Posterior fossa and cerebellopontine (CP) angle cysts were seen in three patients each. Four patients had cerebral convexity cysts, one had an interhemispheric cyst, one had a supraseller cyst, and the one with infantile spasms had a cyst in the periventricular region.

\section{Treatment and Surgical Procedure}

All patients underwent endoscopic procedures depending on the location of the cyst. Cysts present around the ventricles underwent cystoventriculostomy; cystocisternostomy was planned for cysts around the cisterns. Third ventriculostomy was an added procedure in patients with a fourth ventricular outlet obstruction, and the procedure was performed via a precoronal burr hole. All procedures were performed under general anesthesia. Proper positioning of the patient for surgery was planned and determined depending on the cyst location. Preoperative antibiotics were administered 30 minutes before the time of induction. The surgical field was prepared and draped under all aseptic precautions. A curvilinear skin incision was placed and a skin flap was reflected with stay sutures. A burr hole was performed to allow insertion of the neuroendoscope. Both rigid rod and flexible endoscopes (Karl Storz, Germany) were used. A cruciate incision was placed over the dura after adequate coagulation. An endoscopic sheath with trocar was introduced through the burr hole and the lateral ventricle was tapped. The endoscope was negotiated into the cyst through the ventricular cavity or directly into the cyst in some cases. Cyst wall was visualized all around. Continuous irrigation was done with Ringer lactate and gentamycin at $37^{\circ} \mathrm{C}$ by connecting an irrigating channel to the endoscope. The flow was adjusted to maintain an adequate intracystic pressure and to prevent collapse of the cyst wall during the procedure.

After careful examination of the cyst wall, an avascular zone was selected for fenestration. A piece of cyst wall was excised and sent for histopathologic study in all the cases. Stoma was created using a blunt endoscopic bipolar tip or Fogarty catheter. Multiple communications were created between the cyst cavity and cerebrospinal fluid (CSF) pathways. These stomas were dilated as wide as possible with a 3F and 4F Fogarty catheter. CSF cavity and subarachnoid cisterns were examined for any bleeding or adhesions that were also breached. Bleeding from the cyst wall was controlled with continuous Ringer lactate irrigation, by maintaining continuous pressure on the cyst wall with the Fogarty balloon catheter and bipolar coagulation. Third ventriculostomy and aqueductoplasty were performed as and when required. Finally, a reservoir was placed in the burr hole for controlled tapping and to prevent early CSF leak/failure and then anchored to the subcutaneous tissue. No major intraoperative or immediate postoperative complications were encountered. No patient required craniotomy for any untoward complications. All patients were extubated on the table.

\section{Follow-up and Outcome}

All patients had a postoperative CT scan of the brain after 3 to 6 months that showed a significant reduction in the cyst dimensions. One patient had a CSF leak through the surgical wound that was treated conservatively with regular CSF tapping from the reservoir and oral acetazolamide. Three patients had subdural hygroma on follow-up scans but showed clinical improvement with complete resolution of the hygromas over time. One patient with a posterior fossa cyst presented with pseudomeningocele at the reservoir site and required a ventriculoperitoneal shunt for CSF diversion. Overall, all the patients showed symptomatic improvement.

\section{Case 1: Endoscopic Cystoventriculostomy for Intracranial Cysts with Infantile Spasms}

A 7-month-old girl presented with recurrent episodes of sudden forward flexion movements since age 3 months. Her electroencephalogram (EEG) was suggestive of hypsarrhythmia, and CT and MRI of the brain (-Fig. 1) showed a large right occipital juxtaventricular cyst. She was started on intravenous adrenocorticotrophic hormone injections at age 


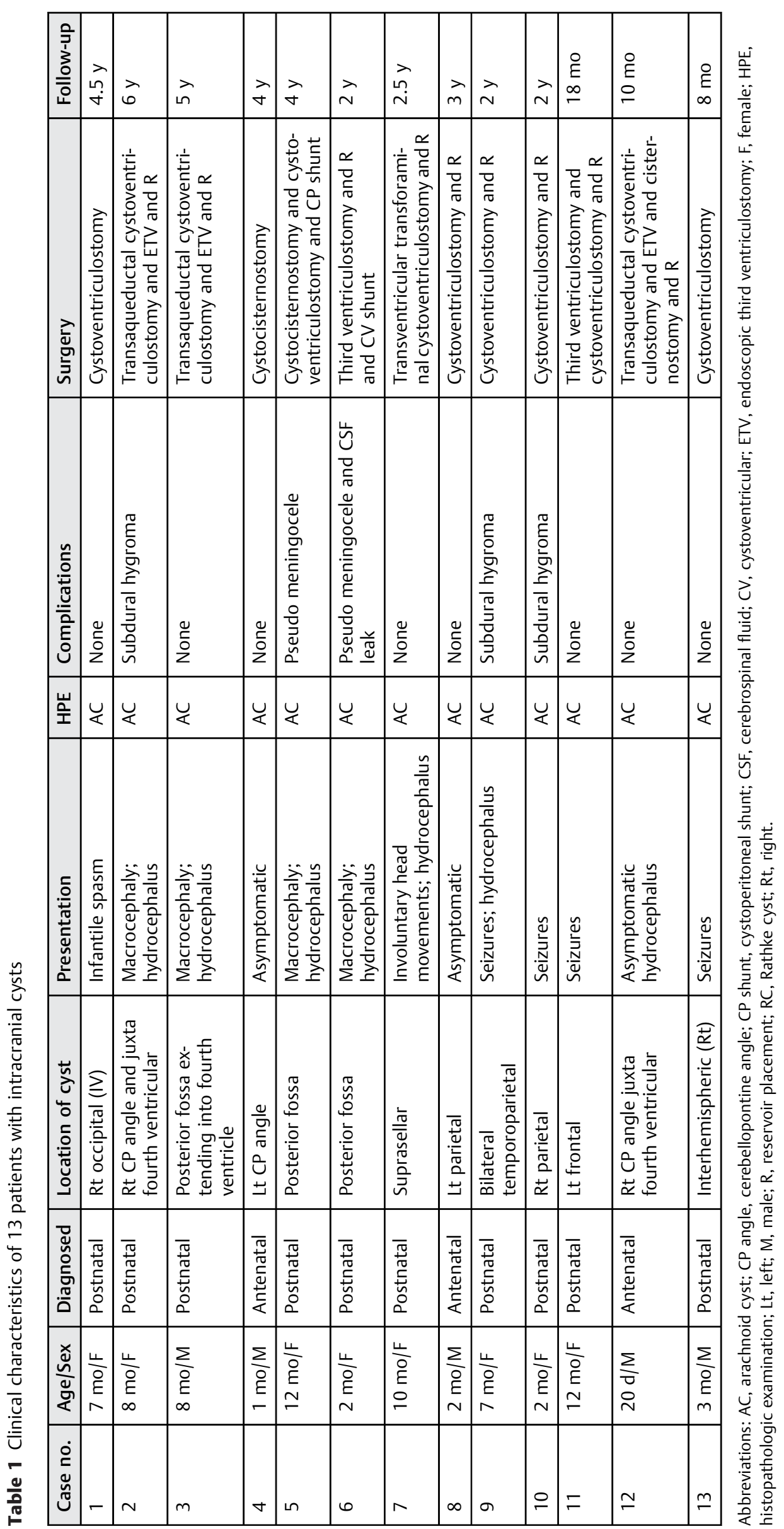




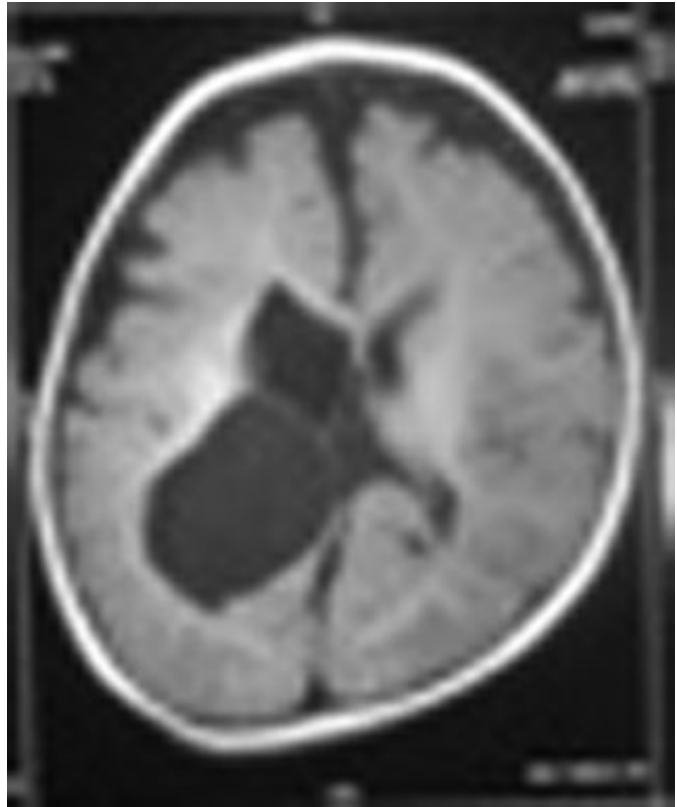

Fig. 1 Case 1: Preoperative magnetic resonance imaging showing a large right periventricular arachnoid cyst presenting with infantile spasm.

5 months. Initially, the patient responded to treatment, but soon her symptoms recurred. Finally, her symptoms and hypsarrhythmia decreased following endoscopic cystoventriculostomy. Her postoperative CT brain scan (-Fig. 2) correlated with the clinical findings and showed a significant reduction in cyst dimensions.

\section{Cases 4 and 5: Endoscopic Cystocisternostomy for Posterior Fossa and Cerebellopontine Angle Cysts}

One patient was diagnosed with a posterior fossa cyst and the other with a CP angle cyst. Endoscopic cystocisternostomy

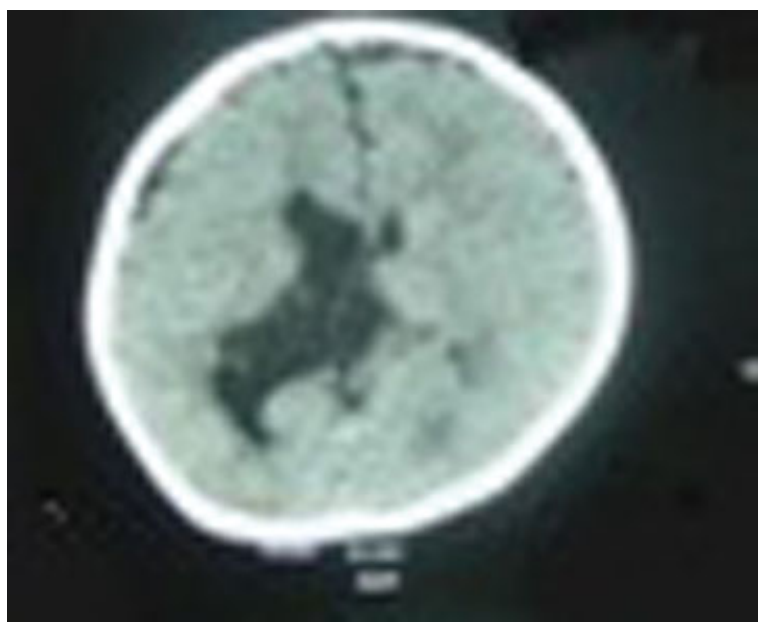

Fig. 2 Case 1: Postoperative computed tomography showing a welldecompressed cyst.

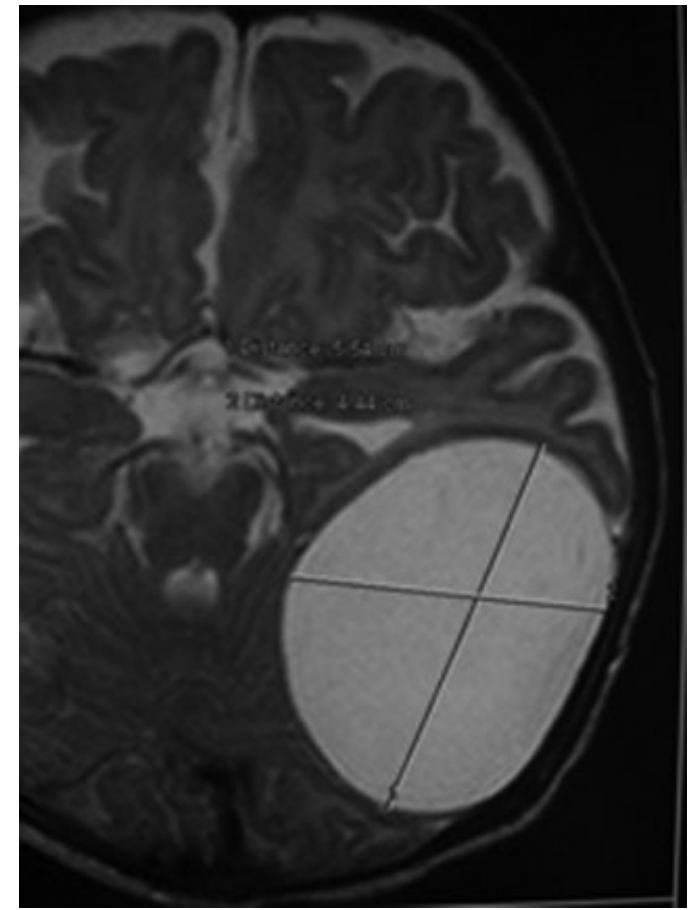

Fig. 3 Case 4: Preoperative magnetic resonance imaging of a leftsided cerebellopontine angle cyst.

(cyst opened into the $\mathrm{CP}$ angle cistern) was performed through an occipital retromastoid burr hole for a 1-monthold asymptomatic boy (case 4) diagnosed antenatally with a large left CP angle cyst (-Fig. 3). A postoperative CT brain scan showed a considerable reduction in the cyst dimensions (-Fig. 4). The patient with the posterior fossa cyst (case 5) was a 12-month-old girl with macrocephaly who also underwent cystocisternostomy and cystoventriculostomy through

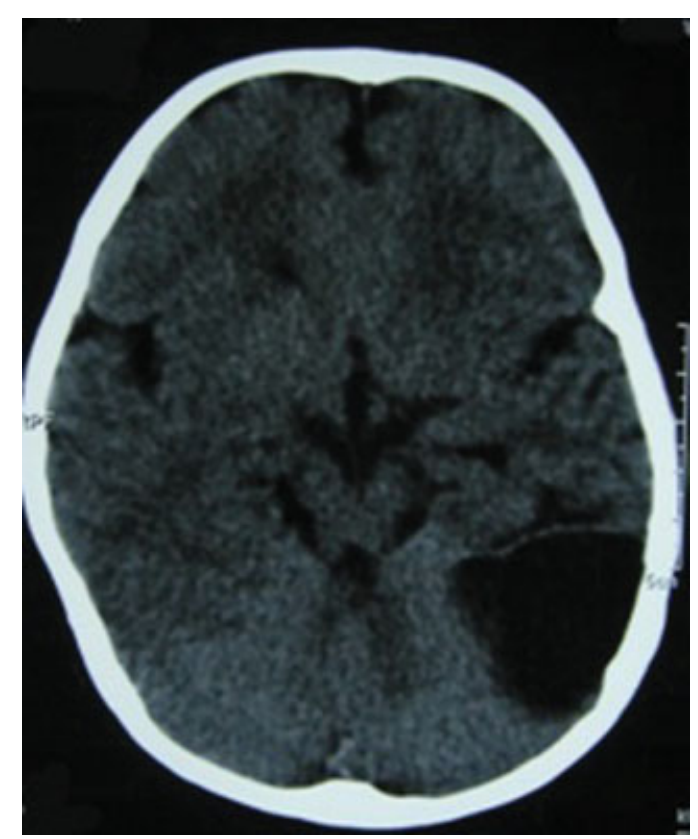

Fig. 4 Case 4: Postoperative computed tomography brain showing reduced cyst size following cystocisternostomy. 


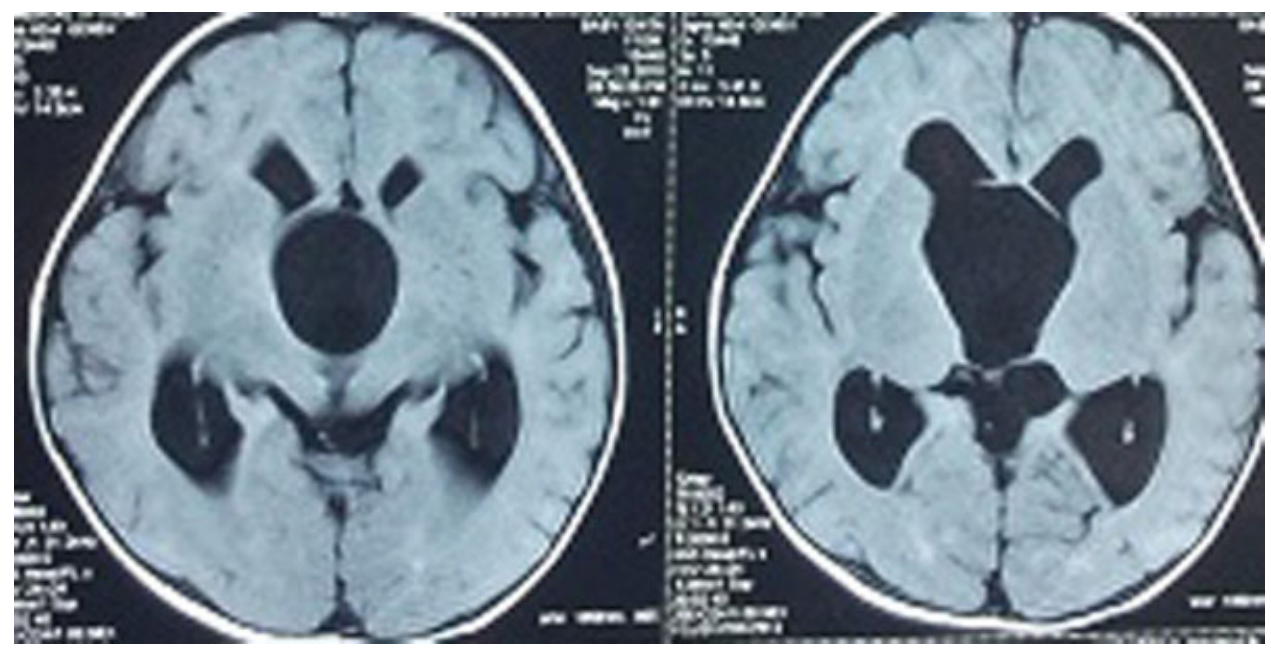

Fig. 5 Case 7: Magnetic resonance imaging brain scan of a 10-month-old girl showing a large suprasellar arachnoid cyst with hydrocephalus.

an occipital burr hole. The cyst was communicated with the fourth ventricle, and then a third ventriculostomy was performed using the classical approach. Later, she presented with a pseudomeningocele at the operative site that required a cystoperitoneal shunt.

\section{Case 6: Endoscopic Third Ventriculostomy with Cystoventricular Shunt for Large Posterior Fossa Cysts}

A 2-month-old girl presented with progressive enlargement of head size since 3 weeks with downward deviation of the eyeballs since 2 weeks. Her MRI showed a large posterior fossa cyst with compression of the cerebellar hemispheres (more on the right side) with gross dilatation of the lateral and third ventricles. Endoscopic third ventriculostomy with reservoir placement followed by a cys- toventricular shunt was performed because the location of the cyst was not adjacent to any CSF pathway (fourth ventricle). A postoperative CT brain scan showed mild reduction in cyst size and mass effect over surrounding structures. The patient developed a CSF leak with a pseudomeningocele in the immediate postoperative period that was managed conservatively.

\section{Case 7: Transventricular Transforaminal Cystoventriculostomy for Suprasellar Cysts}

A 10-month-old girl presented with involuntary head movements. She was diagnosed with a suprasellar cyst with hydrocephalus (-Fig. 5). The patient underwent transventricular transforaminal cystoventriculostomy (cyst opening into the third ventricle) through a classic precoronal burr hole because the cyst was projecting into the third ventricular

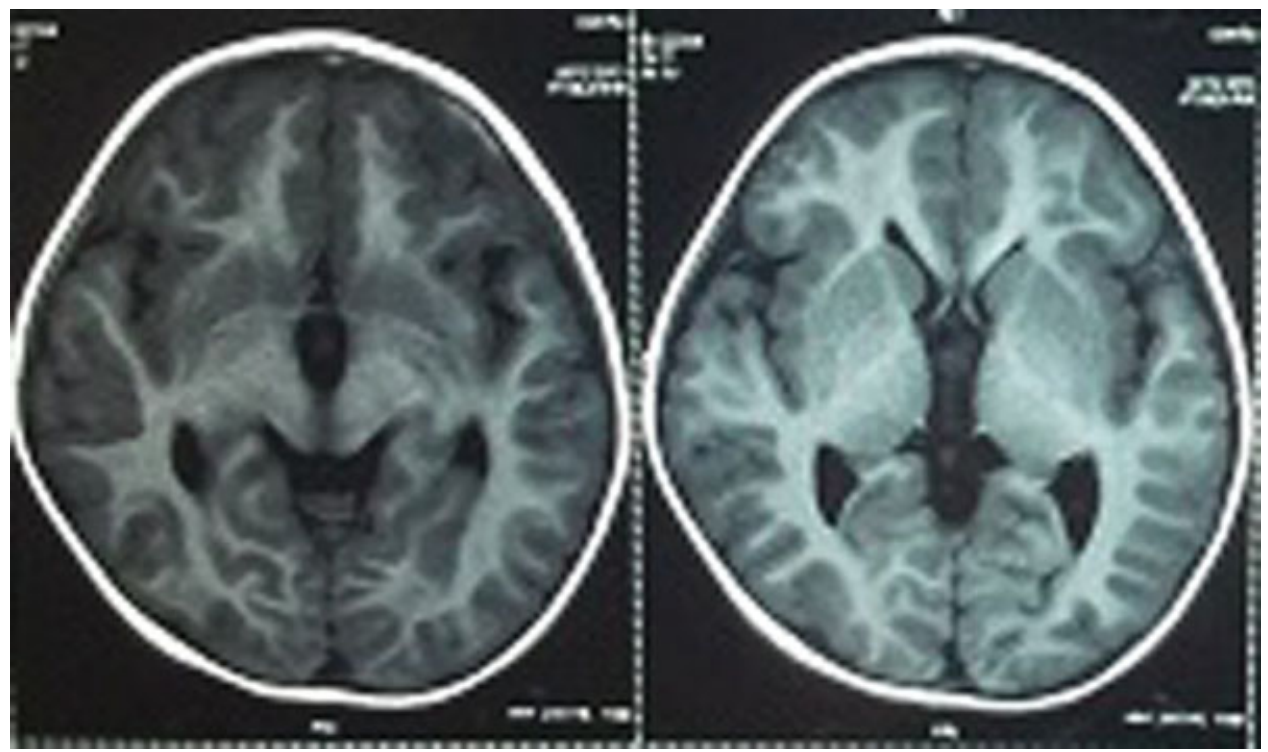

Fig. 6 Case 7: Postoperative magnetic resonance imaging brain scan showing decrease in cyst size with resolved hydrocephalus. 


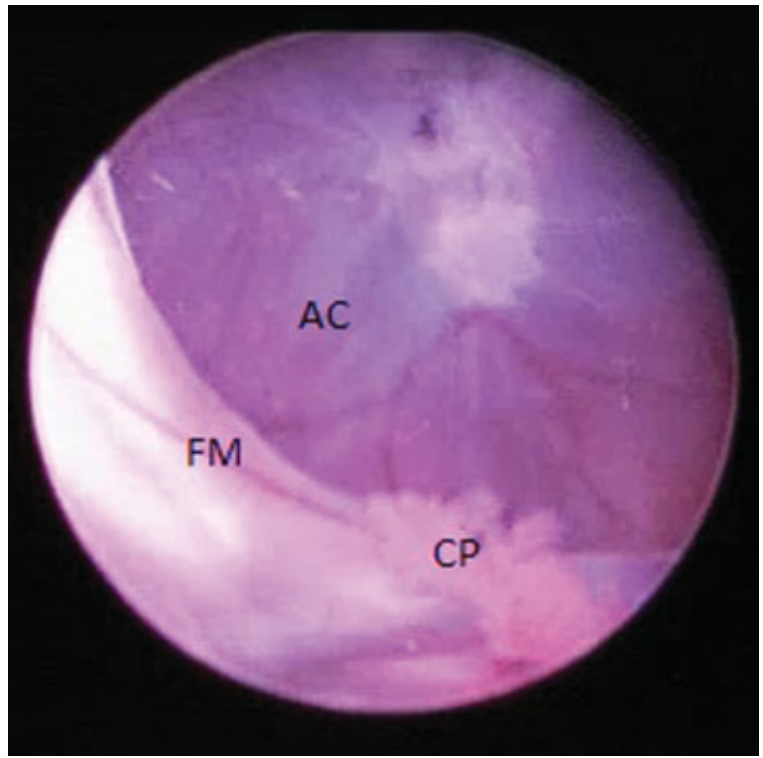

Fig. 7 Case 7: Intraoperative endoscopic view of foramen of Monroe (FM) along with partially collapsed suprasellar arachnoid cyst (AC), choroid plexus (CP).

floor (-Figs. 7 and 8). A reservoir was placed in view of the hydrocephalus. Postoperative MRI showed resolving arachnoid cyst and hydrocephalus (-Fig. 6).

\section{Cases 8 to 11: Endoscopic} Cystoventriculostomy/Cystocisternostomy with Reservoir Placement for Supratentorial Cysts

Four children were diagnosed with supratentorial convexity and paraventricular cysts. - Fig. 9 shows the preopera-

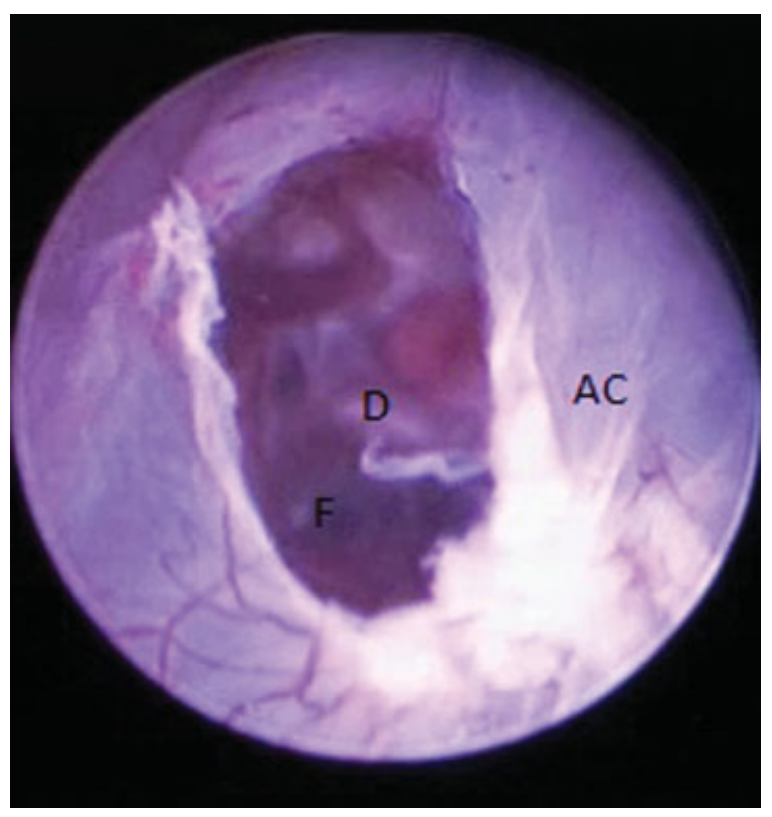

Fig. 8 Case 7: Visualization of the floor of the third ventricle through the marsupialized cyst wall. arachnoid cyst (AC); dorsum sella (D); floor of third ventricle $(\mathrm{F})$.

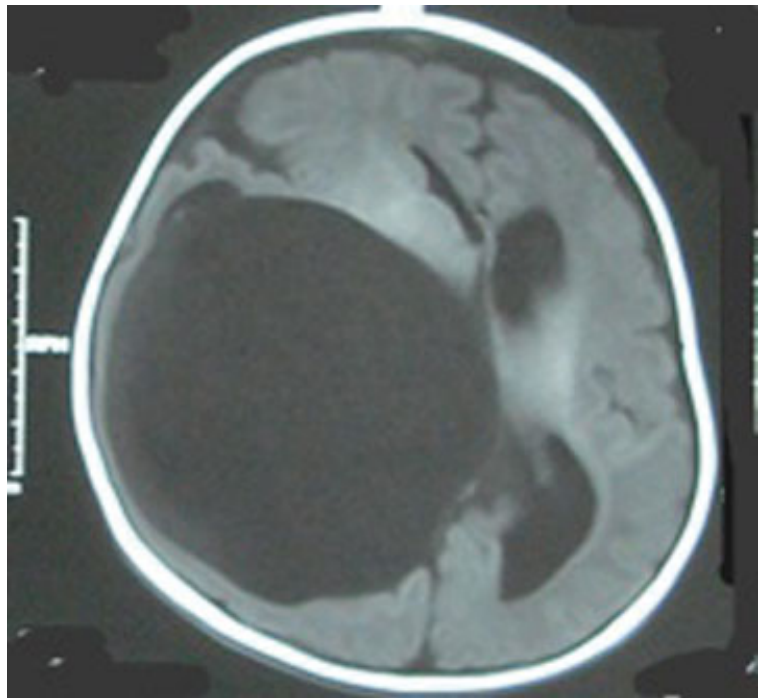

Fig. 9 Case 10: Preoperative magnetic resonance imaging brain scan showing large right parietal paraventricular cyst.

tive MRI of a 2-month-old girl with a large right parietal paraventricular cyst. This child underwent endoscopic cystoventriculostomy (cyst communicated with the lateral ventricle) with reservoir placement. The infants with a cyst in the parietal location (-Fig. 15 preoperative and - Fig. 16 postoperative images) underwent an endoscopic procedure through a parietal burr hole; the patient with a frontal arachnoid cyst underwent the procedure through a frontal burr hole (-Fig. 11). The postoperative CT brain scan (-Fig. 10) showed a considerable decrease in the cyst dimensions with subdural hygroma.

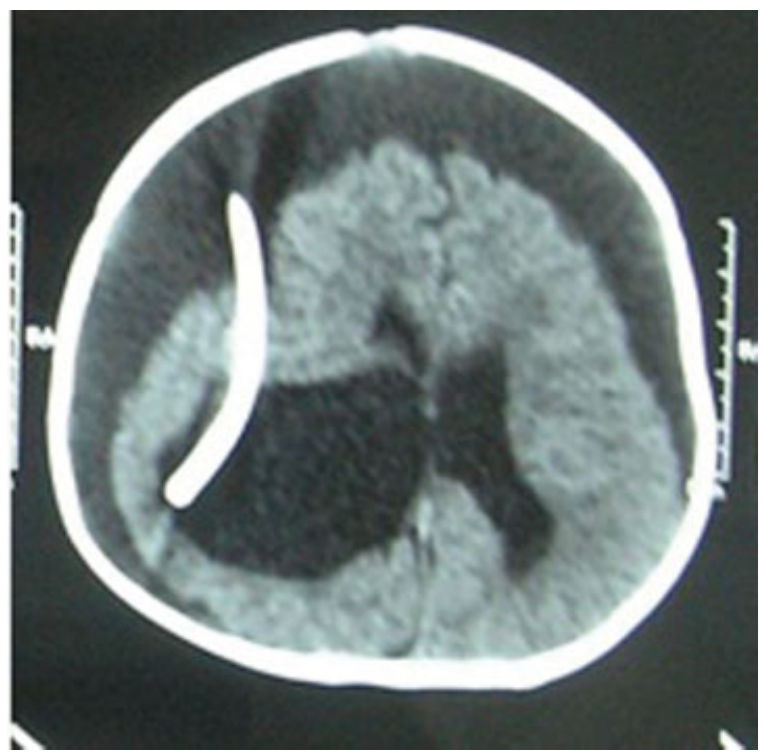

Fig. 10 Case 10: Postoperative computed tomography scan showing reduced cyst size with subdural hygroma. 


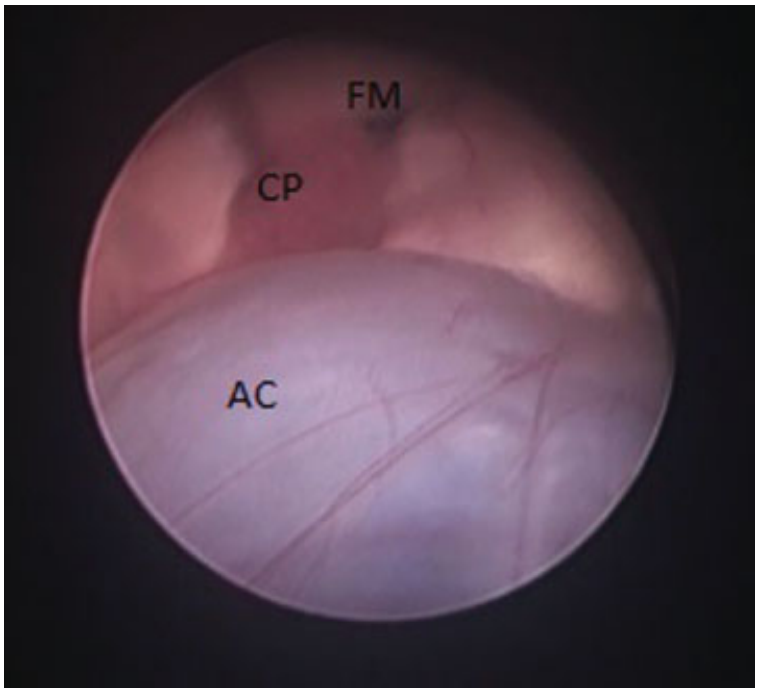

Fig. 11 Case 10: Endoscopic view of the cyst projecting into the lateral ventricle with visualization of choroid plexus and foramen of Monroe (FM). arachnoid cyst (AC); choroid plexus (CP).

\section{Cases 2, 3, and 12: Posterior Fossa Cyst Decompressed through the Transaqueductal Route}

The findings of these cases revealed posterior fossa/CP angle cysts with hydrocephalus that were positioned abutting the fourth ventricle (-Figs. 12 and 13). Due to this fourth ventricle outlet obstruction, the aqueduct was dilated and a transaqueductal procedure was easily feasible ( - Fig. 14). All these patients underwent endoscopic transaqueductal cystoventriculostomy (cyst opened into the fourth ventricle), partial excision of the cyst wall along with a third ventriculostomy, and reservoir placement through a standard precoronal burr hole ( $\mathbf{F i g}$. 17a-c). A flexible endoscope was used in these cases for ease of manoeuvrability through the aqueduct. Fontanelles were lax after the procedure. One child had subdural hygroma on follow-up scan that was treated conservatively. Overall, all the infants showed good symptomatic improvement in the postoperative period.

\section{Case 13: Interhemispheric Arachnoid Cyst}

A 3-month-old boy presented with seizures/tonic posturing. MRI revealed a large interhemispheric arachnoid cyst

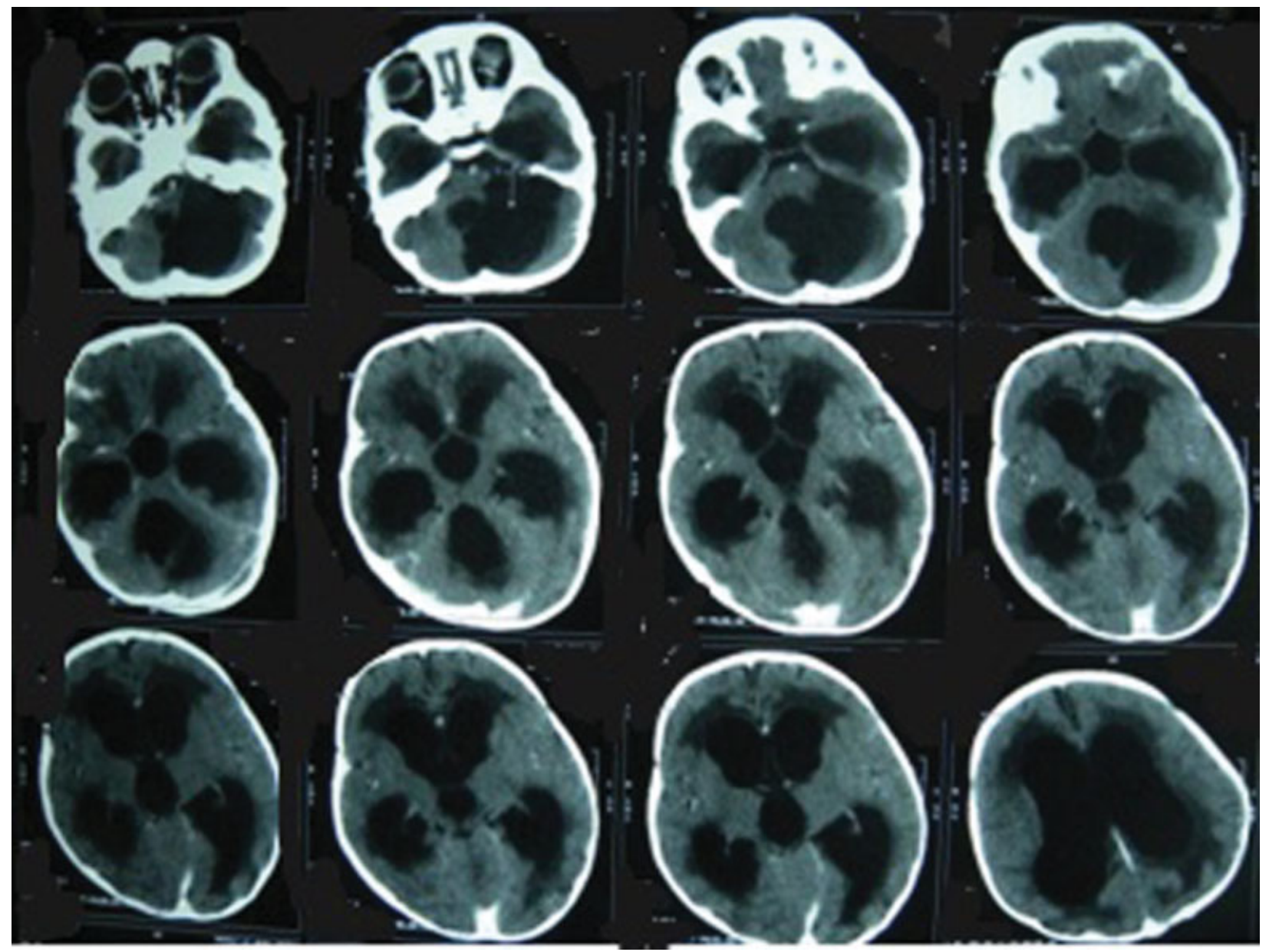

Fig. 12 Case 3: Preoperative computed tomography scan of posterior fossa juxta fourth ventricular arachnoid cyst with hydrocephalus. 


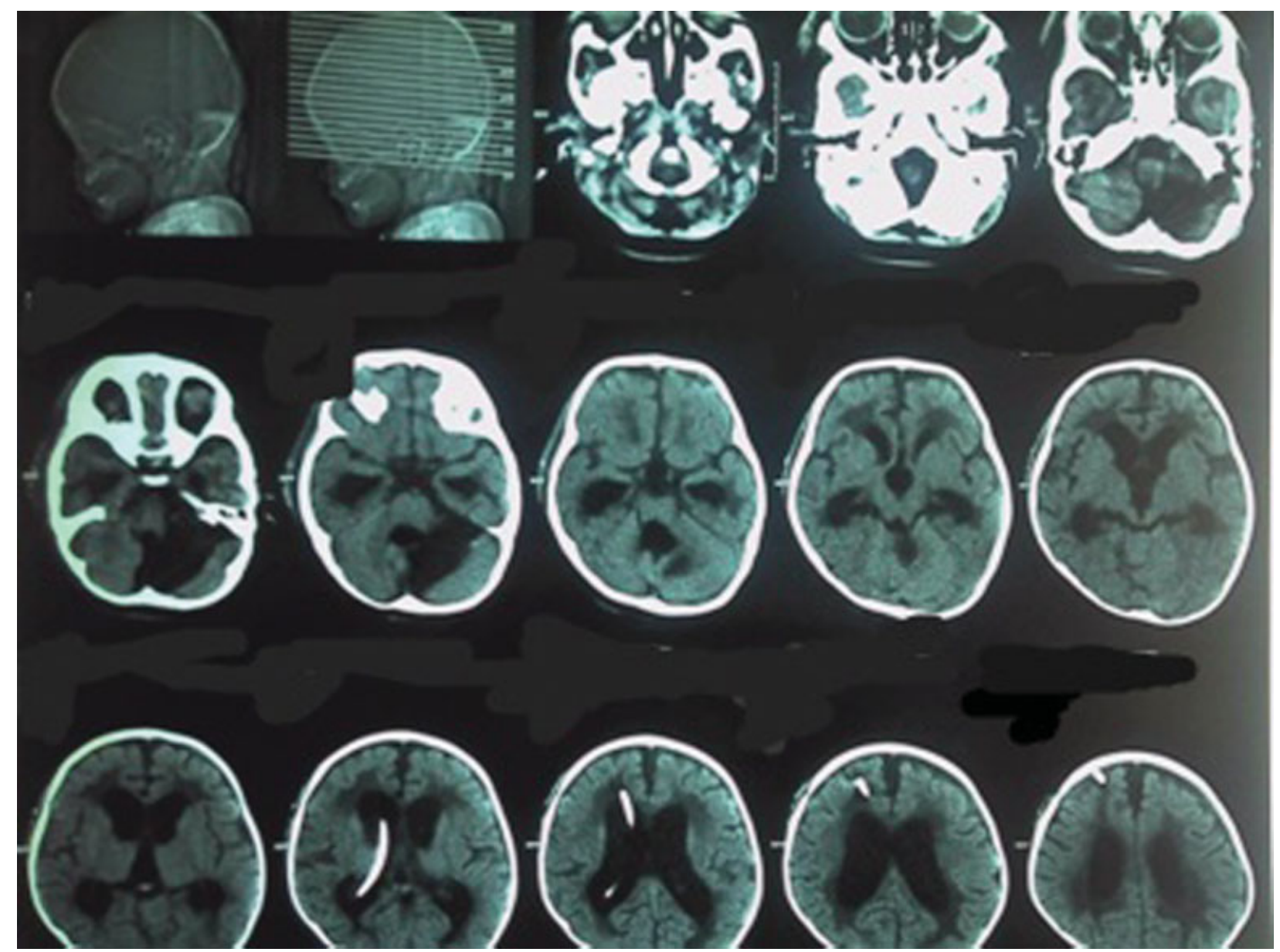

Fig. 13 Case 3: Postoperative computed tomography brain scan showing both the cyst and ventricles well decompressed.

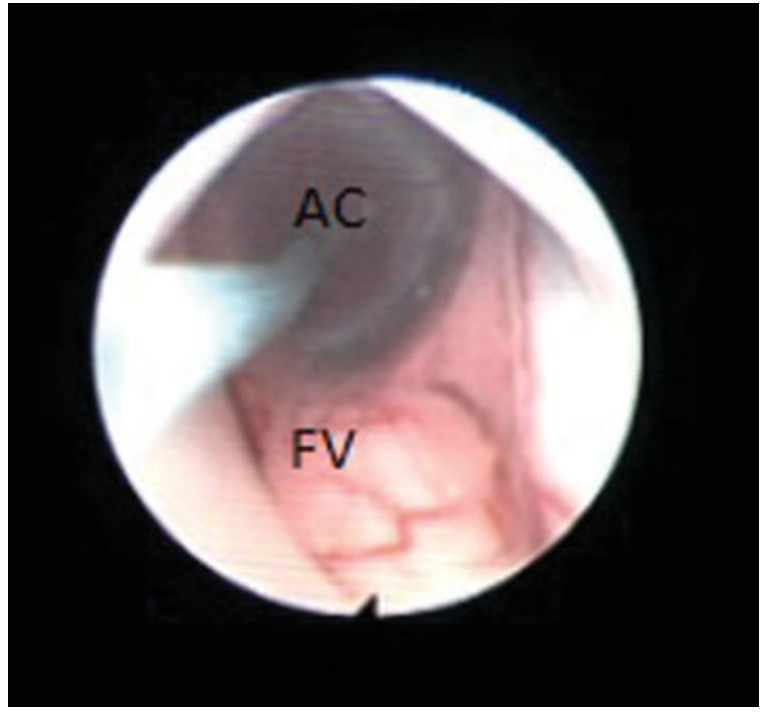

Fig. 14 Case 3: Endoscopic (flexible) view through the aqueduct, of the fourth ventricular arachnoid cyst (AC) being coagulated with the help of a flexible monopolar probe; fourth ventricle (FV).

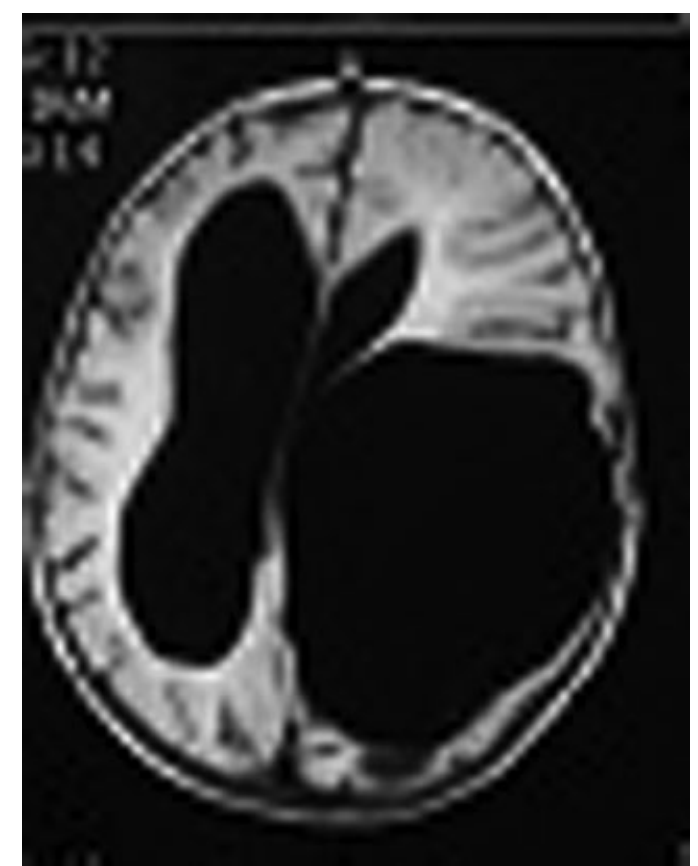

Fig. 15 Case 8: Preoperative images of infant with left parietal arachnoid cyst. 


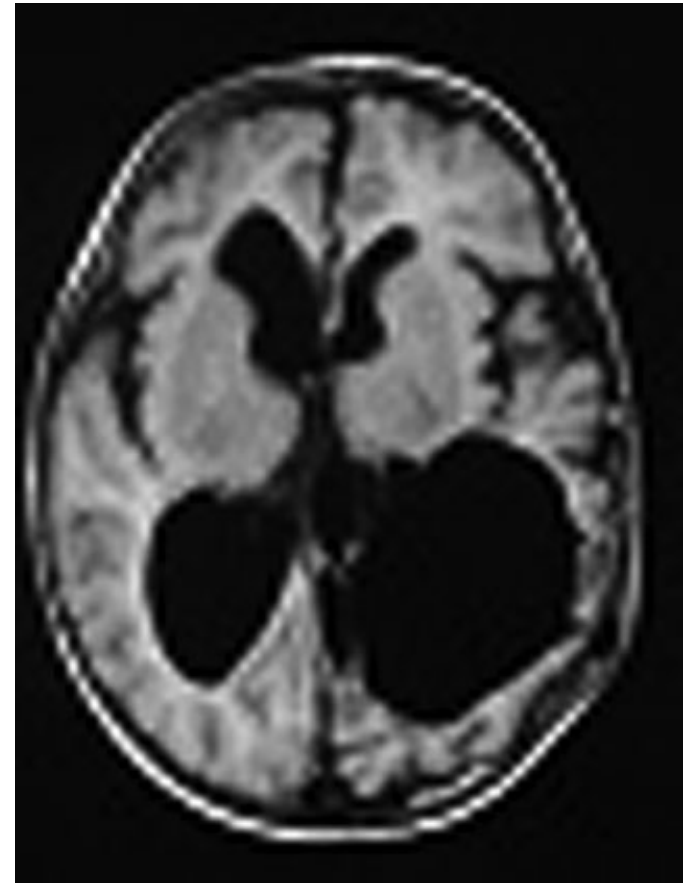

Fig. 16 Case 8: Postoperative image of infant with left parietal arachnoid cyst.

predominantly extending to the right side and corpus callosum agenesis with displacement and compression of the lateral ventricles more laterally (-Fig. 18). The EEG was suggestive of right-side hemispheric discharges. The child underwent an endoscopic cystoventriculostomy via a classical precoronal burr hole. Postoperatively the child did well, and a postoperative scan revealed a decompressed cyst and opened up ventricles and sulcal spaces (-Fig. 19).

\section{Results}

The follow-up period ranged from 8 months to 6 years. All patients were assessed using clinical characteristics, neuropsychological assessment, and follow-up imaging. The patient with infantile spasms showed a decreased frequency of spasms, and the postoperative anticonvulsants required was reduced from four to only one. The EEG also showed decreased episodes of hypsarrhythmia. All patients were relieved symptomatically. Only one patient with a posterior fossa cyst required a CSF diversion procedure because she presented with a pseudomeningocele at the occipital burr hole site 6 months after the primary surgery. Postoperative imaging showed a significant decrease in cyst size in nine patients and a slight decrease in the cyst size in the remaining five. Only one patient had a CSF leak from the surgical wound that was treated conservatively with oral acetazolamide followed by repeated CSF tapping from the reservoir.

\section{Discussion}

Intracranial arachnoid cysts are developmental abnormalities of the arachnoid membrane that get duplicated or split. The other mechanism of arachnoid cyst formation is an incomplete separation of the endomeninx, which is the perimedullary mesh. This occurs during the early embryonic period. ${ }^{2,5,6}$ Arachnoid cysts are also associated with other central nervous system anomalies such as partial or complete agenesis of lobes. These cysts can be diagnosed antenatally with ultrasonography (USG). ${ }^{7}$ In our current series, four cases were diagnosed incidentally in the antenatal period with routine USG. Although asymptomatic, the CSF dynamics can result in an increase in the size of some cysts or rupture leading to elevated intracranial pressure (ICP). The probable mechanisms include active secretions from the cyst wall, a valvelike mechanism that causes inflow of CSF from CSF-filled cavities because of arterial pulsations and obstructed outflow. Others include aberrant fluid dynamics and osmotic changes along the cyst wall. ${ }^{2,5,8}$ This leads to a persistent and continual mass effect that can hinder the normal development and function of the surrounding brain. ${ }^{9-12}$ The management options include either clinical monitoring with serial MR imaging and timely intervention or elective definitive surgery for a large asymptomatic cyst. Young patients are prone to cyst enlargement and hence need surgical interventions as early as possible. ${ }^{13}$
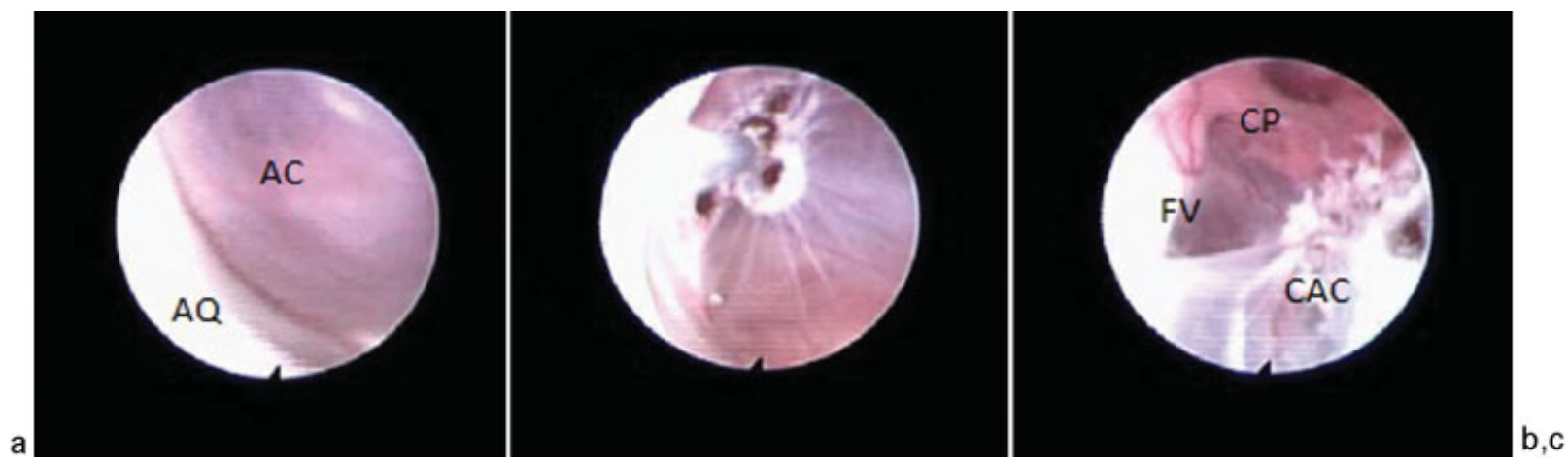

Fig. 17 (a) Case 12: Flexible endoscope used to visualize the fourth ventricular (FV) arachnoid cyst (AC) through the aqueduct (AQ). (b) The cyst being marsupialized and coagulated led to a complete collapse of the cyst and visualization of the fourth ventricular (FV) choroid plexus (CP). (c) Complete collapse of the cyst and visualization of the fourth ventricular (FV), choroid plexus (CP); collapsed arachnoid cyst (CAC). 


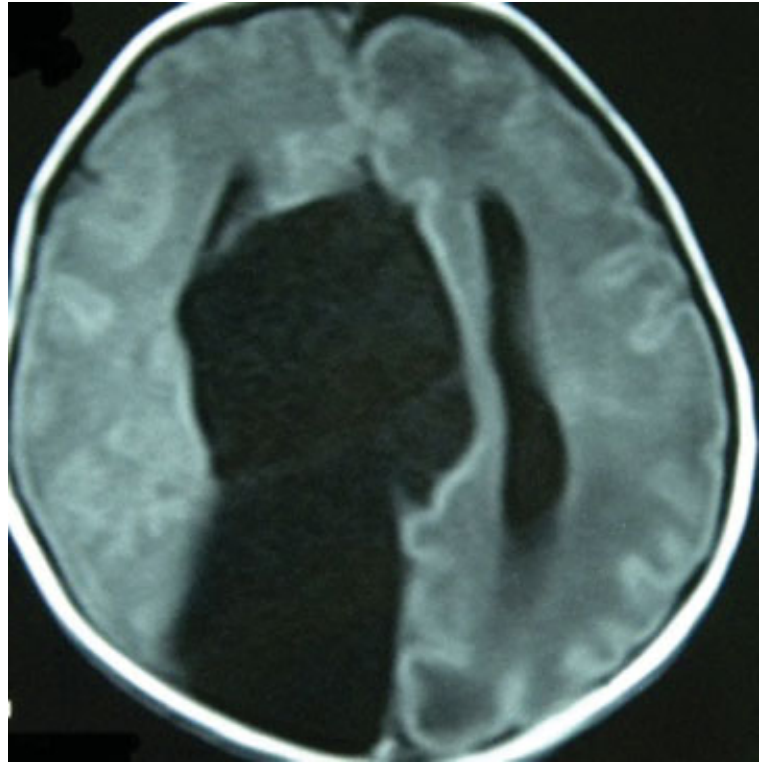

Fig. 18 Case 13: Magnetic resonance images showing large interhemispheric arachnoid cyst displacing and compressing the lateral ventricles (right to left).

The symptomatology depends on the location of the cyst and age of the patient. Supratentorial cysts can be both intraor extra-axial and usually present with macrocephaly or elevated ICP. Suprasellar cysts usually present with typical bobble-head doll syndrome and endocrine or visual abnormalities. Hydrocephalus is a common manifestation in posterior fossa cysts and periventricular cysts either due to compression of the fourth ventricle or aqueduct causing fourth ventricular outflow obstruction. In neonates and younger children, presenting symptoms are usually due to elevated ICP. In our case series, common presenting symp-

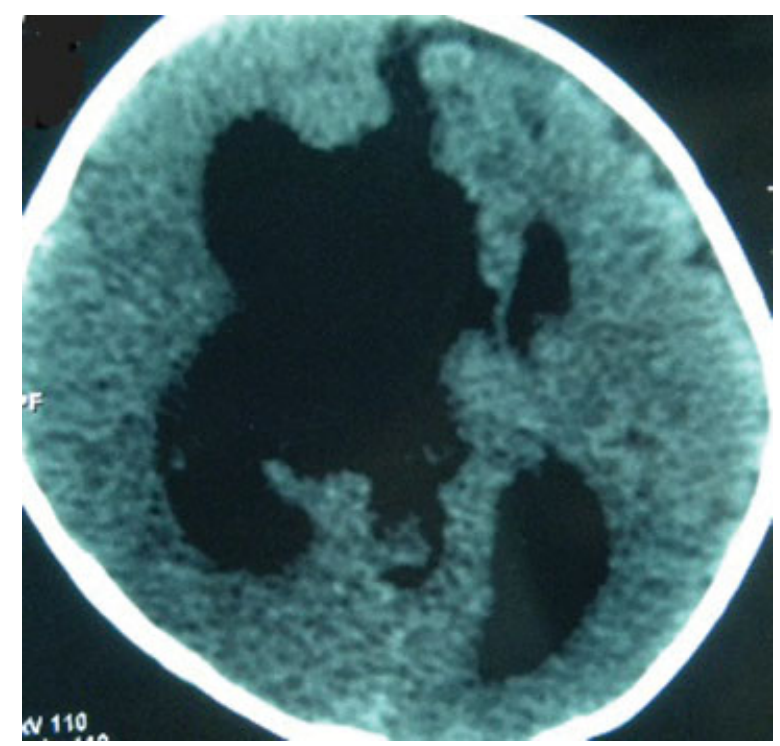

Fig. 19 Case 13: Postoperative computed tomography showing decompressed cysts and opened up lateral ventricles. toms were macrocephaly, hydrocephalus, and seizures. Other symptoms encountered were poor gaze fixation, infantile spasms, and involuntary forward flexion movements of the head.

Varied surgical options have been described for intracranial cysts, but the optimal option is still debated. These include simple burr hole and cyst aspiration, cyst shunting, ventricular shunting, microsurgical cyst excision, endoscopic fenestrations of cysts, and marsupialization of the cyst wall. Age is not a limiting factor for these surgical options. ${ }^{14}$ Sikorski et al concluded that endoscopic fenestration is the preferred initial surgical management of symptomatic intracranial cysts in infants $\leq 1$ year of age. ${ }^{4}$ Pros and cons of different surgical options are described in - Table 2 .

The major goals of the surgery for intracranial cysts are decompression of the cyst and preventing further compression of neural structures. Endoscopic decompression of the cyst is minimally invasive, less time consuming, safe, and easy with a decreased incidence of postoperative complications. Other endoscopic procedures include endoscopic cystocisternostomy, cystoventriculostomy, or partial cyst wall excision.

Most arachnoid cysts do not resolve completely as seen in our case series. In this series, postoperative imaging showed a significant decrease in cyst size in seven patients and only a slight decrease in cyst size with a resolution of symptoms in others. The reason for noncollapsibility of these cysts is that they are developmental cysts and associated with agenesis of lobes. ${ }^{2,5,8}$

In this current series, endoscopic fenestration helped successfully in decreasing the frequency of seizures. Koch et al reported 37 cases with seizures and found that $23(62 \%)$ were seizure free postoperatively, nine patients (24\%) had a reduction of seizures, and five children (14\%) remained unchanged. ${ }^{15}$

All types of cysts can be treated with endoscopic fenestrations. ${ }^{15,16}$ In our case series, suprasellar, supratentorial, infratentorial, paraventricular, posterior fossa, and CP angle cysts were successfully treated with endoscopic cystoventriculostomy or cystocisternostomy. Hopf and Perneczky used different endoscopic techniques in 36 patients with intracranial cysts and concluded that intraventricular and suprasellar cysts are better managed with endoscopic neurosurgery. ${ }^{17}$ Endoscopic fenestration is a minimally invasive technique that is a safe and effective alternative treatment for suprasellar arachnoid cysts. ${ }^{14,18}$

Posterior fossa cyst is another challenge for the neurosurgeon. These cysts as in cases of fourth ventricular outlet obstruction can cause obstructive hydrocephalus and also decrease the prepontine space, thus making third ventriculostomy difficult. ${ }^{19}$ Posterior fossa cysts bulging into the fourth ventricle could easily be accessed through the transaqueductal approach using a flexible neuroendoscope. This procedure of transaqueductal cyst decompression with a flexible endoscope was not described in the literature. This procedure thus avoids the more aggressive treatment options like shunting the cyst or a major craniotomy and cyst excision. Reservoir placement after the endoscopic procedure is an 
Table 2 Advantages and disadvantages of the different surgical techniques

\begin{tabular}{|l|l|l|}
\hline Procedure & Advantages & Disadvantages \\
\hline Cyst shunting & $\begin{array}{l}\text { Safe procedure; useful in distorted anatomy of } \\
\text { ventricles }\end{array}$ & $\begin{array}{l}\text { - Shunt infection, dependency, and failure } \\
\text { - Need for revisions }\end{array}$ \\
\hline Ventricular shunting & Decreases raised ICP & $\begin{array}{l}\text { - All disadvantages of cyst shunting } \\
\text { - Cyst may persist and continue to grow and } \\
\text { cause mass effect }\end{array}$ \\
\hline Microsurgical cyst excision & $\begin{array}{l}\text { Whole cyst can be visualized; multiple } \\
\text { fenestrations; less blood loss }\end{array}$ & $\begin{array}{l}\text { - Relatively more time consuming and a more } \\
\text { invasive technique } \\
\text { - More brain handling and likely increased } \\
\text { tissue damage in deep-seated cysts com- } \\
\text { pared with endoscopic fenestration }\end{array}$ \\
\hline Endoscopic fenestrations & $\begin{array}{l}\text { Less time consuming; easy and safe; compara- } \\
\text { tively less blood loss }\end{array}$ & $\begin{array}{l}\text { - Requires trained personnel and equipment } \\
\text { Reformation of membrane }\end{array}$ \\
\hline Marsupialization & Less recurrence & - Same as microsurgical cyst excision \\
\hline
\end{tabular}

Abbreviation: ICP, intracranial pressure.

additional technique for postoperative CSF access for controlled tapping and as a preventive measure for early CSF leak, which is major concern for any neurosurgeon.

\section{Conclusion}

No generally accepted solution exists for the treatment of intracranial cystic lesions including arachnoid cysts. There has always been controversy regarding the best surgical option. For some cysts, a permanent solution like endoscopic fenestration is possible. Endoscopic neurosurgery in experienced hands is an easy, safe, and less invasive surgical technique. The surgical approach has to be tailored according to the location of the cyst. A flexible endoscope is a useful adjunct in selected cases where a rigid scope cannot be manoeuvred. Outcome with neuroendoscopic procedure in infants is as effective as in older children. The endoscopic procedure does not cause the complete collapse of the cyst, but it definitely alters the fluid dynamics resulting in shrinkage of the cyst and decreasing mass effect. It prevents major perioperative and postoperative complications and avoids diversionary procedures in most cases.

\section{References}

1 Epelman M, Daneman A, Blaser SI, et al. Differential diagnosis of intracranial cystic lesions at head US: correlation with CT and MR imaging. Radiographics 2006;26(1):173-196

2 Rengachary SS. Intracranial arachnoid and ependymal cysts. In: Wilkins RH, Rengachary SS, eds. Neurosurgery. 2nd ed. New York, NY: McGraw-Hill; 1985:2160-72

3 Rappaport ZH. Suprasellar arachnoid cysts: options in operative management. Acta Neurochir (Wien) 1993;122(1-2):71-75

4 Sikorski CW, Yamini B, Frim DM. Endoscopic cyst fenestration outcomes in children one year of age or less. Pediatr Neurosurg 2004;40(2):59-63

5 Rengachary SS, Kennedy JD. Intracranial arachnoid cysts and ependymal cysts. In: Wilkins RH, Rengachary SS, eds. Neurosurgery. 2nd ed. New York, NY: McGraw-Hill; 1996:3709-28
6 Nicholas M, Marion L. Arachnoid cysts. In: Winn HR, ed. Youmans Neurological Surgery. 6th ed. Philadelphia, PA: Saunders/Elsevier; 2011:1911-17

7 Diakoumakis EE, Weinberg B, Mollin J. Prenatal sonographic diagnosis of a suprasellar arachnoid cyst. J Ultrasound Med 1986;5(9):529-530

8 Oberbauer RW, Haase J, Pucher R. Arachnoid cysts in children: a European co-operative study. Childs Nerv Syst 1992;8(5):281-286

9 Caemaert J, Abdullah J, Calliauw L, Carton D, Dhooge C, van Coster R. Endoscopic treatment of suprasellar arachnoid cysts. Acta Neurochir (Wien) 1992;119(1-4):68-73

10 Galassi E, Piazza G, Gaist G, Frank F. Arachnoid cysts of the middle cranial fossa: a clinical and radiological study of 25 cases treated surgically. Surg Neurol 1980;14(3):211-219

11 Raffel C, McComb JG. To shunt or to fenestrate: which is the best surgical treatment for arachnoid cysts in pediatric patients? Neurosurgery 1988;23(3):338-342

12 Schroeder HW, Gaab MR. Endoscopic observation of a slit-valve mechanism in a suprasellar prepontine arachnoid cyst: case report. Neurosurgery 1997;40(1):198-200

13 Al-Holou WN, Yew AY, Boomsaad ZE, Garton HJ, Muraszko KM, Maher CO. Prevalence and natural history of arachnoid cysts in children. J Neurosurg Pediatr 2010;5(6):578-585

14 Yadav YR, Parihar V, Sinha M, Jain N. Endoscopic treatment of the suprasellar arachnoid cyst. Neurol India 2010;58(2):280-283

15 Koch CA, Moore JL, Krähling KH, Palm DG. Fenestration of porencephalic cysts to the lateral ventricle: experience with a new technique for treatment of seizures. Surg Neurol 1998;49(5): 524-532; discussion 532-533

16 Gangemi M, Colella G, Magro F, Maiuri F. Suprasellar arachnoid cysts: endoscopy versus microsurgical cyst excision and shunting. Br J Neurosurg 2007;21(3):276-280

17 Hopf NJ, Perneczky A. Endoscopic neurosurgery and endoscopeassisted microneurosurgery for the treatment of intracranial cysts. Neurosurgery 1998;43(6):1330-1336; discussion 1336-1337

18 Ozek MM, Urgun K. Neuroendoscopic management of suprasellar arachnoid cysts. World Neurosurg 2013;79(2, Suppl):e13-e18

19 Longatti P, Fiorindi A, Feletti A, Baratto V. Endoscopic opening of the foramen of magendie using transaqueductal navigation for membrane obstruction of the fourth ventricle outlets. Technical note. J Neurosurg 2006;105(6):924-927

20 Esmaeeli B, Eftekhar B. Intraparenchymal hemorrhage after surgical decompression of a Sylvian fissure arachnoid cyst. Neurol India 2006;54(3):320-321 